\title{
Liver tumours temper hopes for gene-therapy technique
}

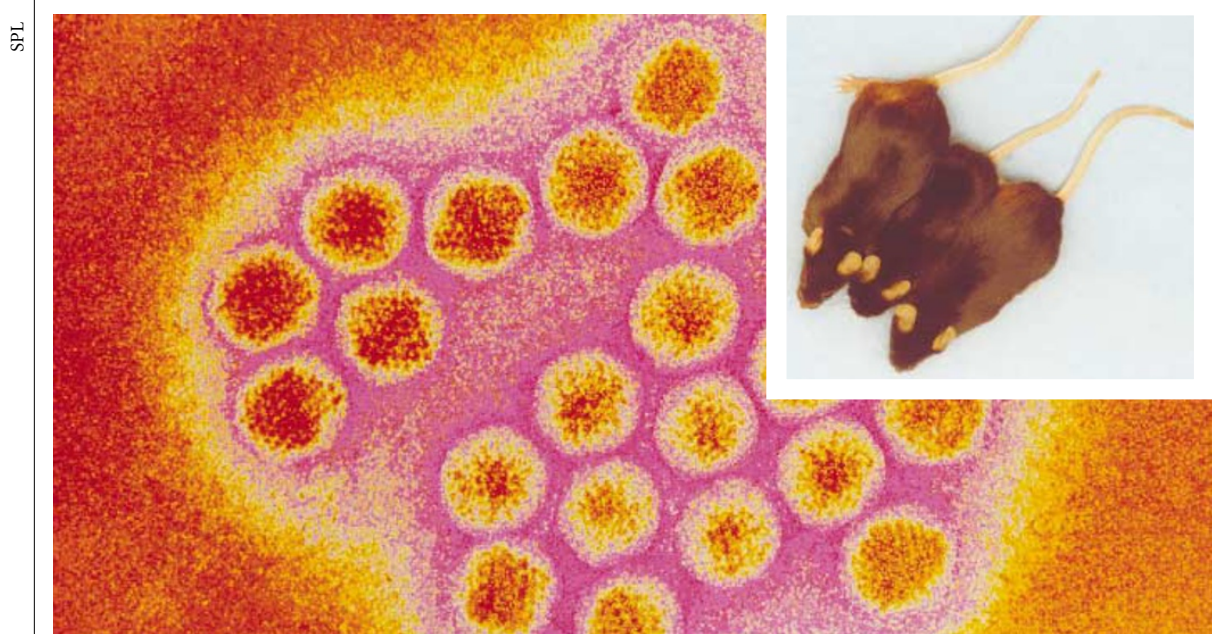

Is it safe for humans to receive genes from adenoviruses like those used to treat mice?

Helen Pearson

A promising approach to gene therapy received an important fillip this week with the publication of two papers suggesting that it can effectively treat rare diseases in mice. But a third paper raises questions about the safety of the technique after tumours were found in older mice that had been used in one of the studies.

The existence of the tumours, whose cause remains unclear, has led to calls for more long-term toxicity studies in animals to be completed before such techniques are used in human trials.

Their discovery, by researchers at Washington University in St Louis, Missouri, is reported in this month's edition of Gene Therapy alongside two sets of positive findings on the use of the technique - one from the Washington University group, the other from researchers at the University of Florida at Gainesville. The two groups joined forces to publish the cautionary paper.

The technique in question uses an adenoassociated virus (AAV), which is not linked to human disease and is therefore considered relatively safe, to deliver normal genes that can substitute for genes containing diseasecausing mutations. It is regarded as one of the most exciting prospective approaches to gene therapy.

Last December, a team led by Mark Sands of Washington University found liver tumours in 6 out of 59 mice, 18 months after they had received a single AAV injection for the rare genetic disease mucopolysaccharidosis type VII. At the time, says Sands, "it got me really nervous".

Despite the discovery of the liver tumours, the Food and Drug Administration (FDA) has given permission for the use of AAV to continue in human clinical trials for cystic fibrosis and haemophilia B.

The US authorities have been cautious about gene-therapy experiments since the death of Jesse Gelsinger in a gene-therapy trial at the University of Pennsylvania in September 1999. Sands' findings initially prompted an immediate halt of human clinical trials using AAV last December. The trials were reinstated by the FDA in January, on the grounds that other research groups working with AAV had failed to find similar tumours in their older animals.

Some think the authorities overreacted in halting the trials in the first place. "It was a bit drastic," says AAV researcher Robin Ali of the Institute of Ophthalmology in London.

Others say the FDA was right to exercise diligence. "You have to take any theoretical risk extremely seriously," says Duncan Geddes, a cystic-fibrosis clinician at the Royal Brompton Hospital in London.

The assessment of the tumour problem published by Sands' group suggests that it was unlikely to have been caused by AAV, because the researchers had found insufficient sign of the virus DNA. But the authors say that they cannot entirely exclude the possibility that AAV caused the tumours.

The latest result is unlikely to be the last word on discussions about the safety of AAV. Researchers say that more priority should be given to long-term toxicity studies of such treatments in animals. These expensive studies require thousands of animals, and often take place only after initial human trials are already under way.

"It might be worthwhile doing them earlier," suggests Terry Flotte of the University of Florida, one of the authors of the second study that found the technique to be effective in mice.

http://www.naturesj.com/gt
Celera and Motorola brought in to aid hunt for disease genes

Jonathan Knight, San Francisco

A public-private research consortium has contracted two companies, Motorola and Celera, to develop a tool to find genes involved in heritable diseases.

The tool is a statistical map of inheritance patterns of single-nucleotide polymorphisms (SNPs), the sequence variants scattered throughout the genome that account for most genetic differences between individuals. The information will help researchers find areas of the genome associated with hereditary diseases.

The SNP Consortium - a collaboration of university sequencing centres, ten pharmaceutical companies and the Wellcome Trust, a British medical research charity - has so far compiled a public list of almost 2 million SNPs.

Because they vary from person to person, SNPs are effective markers for tracking genetic regions through family histories. But because chromosomes exchange DNA with each generation, researchers need to know the probability of nearby SNPs staying together.

In the collaboration, announced on 28 August, the sequencing firm Celera, of Rockville, Maryland, and the life sciences unit of Motorola, in Deerfield, Illinois, will chart inheritance patterns of 2,000 SNPs in 650 people from 50 families. Although Celera claims to have identified more than 3 million SNPs, only public data will be used in this project. Financial details have not been disclosed.

The map is due to be completed by the end of this year. A plan announced in July to produce a much more detailed map of up to 1.5 million SNPs is expected to take several years (see Nature 412 , 105; 2001).

The small number of SNPs being mapped in the Celera-Motorola project will be useful only for studies within families. Studies of the population at large, in which genetic recombination has been much more extensive, will require larger numbers of SNPs.

Current linkage maps use another genetic variant, microsatellites, which have been very effective, says David Altshuler, a geneticist at Harvard Medical School and leader of a team that published 1.4 million SNPs earlier this year.

He expects people to jump on the SNP bandwagon as technology for detecting them improves. "No one is pouring a lot of money into making microsatellite genotyping cheaper and easier," he says. "But a lot of companies are making SNP genotyping cheaper and easier." 